\title{
IDENTIFICAÇÃO DAS PARTES INTERESSADAS EM PROJETO DE IMPLEMENTAÇÃO DO SISTEMA CICLOVIÁRIO NO ENTORNO DAS ESTAÇÕES DO METRÔ DA CIDADE DO RIO DE JANEIRO
}

\author{
Mariana Rodrigues de Figueiredo Moreira \\ Graduada em Arquitetura e Urbanismo \\ Gestão e Gerenciamento de Projetos (GGP), NPPG/UFRJ, RJ, Brasil \\ mariana.defigueiredo@yahoo.com.br
}

José Luiz Fernandes

Pós-Doutor em Engenharia (UFRJ), RJ, Brasil

Professor do Curso de Engenharia de Produção do Centro Federal de Educação Tecnológica Celso Suckow da Fonseca - CEFET/RJ.

jluizfernandes@gmail.com

\section{Eduardo Linhares Qualharini}

Pós-Doutor em Engenharia (UFF), RJ, Brasil

Professor do Curso de Engenharia Civil da Universidade Federal do Rio de Janeiro e Coordenador do Núcleo de Pesquisas em Planejamento de Gestão - NPPG/UFRJ.

qualharini@poli.ufrj.br

\section{Andréa Sousa da Cunha Fernandes}

Mestre em Ciências (UFRJ), RJ, Brasil

Professora do Curso de Engenharia Civil do Centro Federal de Educação Tecnológica

Celso Suckow da Fonseca - CEFET/RJ

andreascunha@gmail.com 


\title{
RESUMO
}

O presente artigo aborda o uso da bicicleta como alternativa de transporte e uma análise conceitual a respeito da atual situação de mobilidade enfrentada pelas metrópoles brasileiras. Neste trabalho também é tratado o poder de articulação e reordenação da bicicleta em malhas urbanas consolidados para o automóvel. Neste trabalho identifica-se as variáveis críticas por meio das análises SWOT, PESTEL e mapeamento de processos e traça-se uma diretriz através do mapeamento das partes interessadas aplicado a um estudo de implementação do sistema cicloviário no entorno da linha metroviária da cidade do Rio de Janeiro de maneira a garantir uma integração com o modal.

Palavras-chave: Análise SWOT e PESTEL. Mobilidade. Partes Interessadas.

\section{IDENTIFICATION OF INTERESTED PARTIES IN THE PROJECT OF IMPLEMENTING THE CICLOVIÁRIO SYSTEM IN THE ENVIRONMENT OF THE METRO STATIONS OF THE CITY OF RIO DE JANEIRO}

\begin{abstract}
This article addresses the use of the bicycle as an alternative mode of transport and conducts a conceptual analysis regarding the current situation of mobility faced by Brazilian cities. In this paper the power of articulation and reorganization of the bicycle in urban networks consolidated for the motor car is also examined. In this work the critical variables are identified, SWOT and PESTEL and process mapping are conducted and a template, by means of mapping of the interested parties, applied to a study of the implementation of the cycle path system around the subway line of the city of Rio de Janeiro is outlined to ensure integration with the transportation modal.
\end{abstract}

Keywords: Bicycle. Mobility. Interested parties. 


\section{INTRODUÇÃO}

Nos dias de hoje é notável problemas de mobilidade nas grandes metrópoles brasileiras, as cidades projetadas para os carros precisam ser reestruturadas de modo a garantir uma infraestrutura de qualidade aos pedestres, ciclistas e transportes públicos.

A bicicleta tem desempenhado um papel significativo de reorganização do território em cidades onde o tecido urbano consolidado foi projetado para o automóvel. A inserção deste meio como uma alternativa de transporte permite comprovar a sua eficiência principalmente em trajetos de até $5 \mathrm{~km}$.

Tendo em vista os grandes congestionamentos em diversas cidades do Brasil este artigo tem como objetivo identificar as partes interessadas de um estudo que visa reduzir o fluxo de veículos a partir da implementação de um sistema cicloviário no entorno das estações do metrô de modo a gerar a integração com o mesmo e atrair novos usuários ao modal, consequentemente reduzir a emissão de gases poluentes, proporcionar uma melhora na saúde das pessoas e vivência na cidade.

Esta pesquisa visa mostrar a importância de identificar as variáveis críticas que envolvem as partes interessadas de um projeto de implementação do sistema no entorno da linha metroviária da cidade do Rio de Janeiro.

\section{DESENVOLVIMENTO}

\subsection{Revisão de Literatura}

Em virtude dos grandes congestionamentos presentes em diversas cidades no mundo o interesse no estudo e pesquisas entorno do planejamento de cidades sustentá- 
veis tem crescido nos últimos anos. O esgotamento dos combustíveis fósseis, a emissão de gases poluentes e ameaça ao clima são considerados estímulos na busca por uma cidade viva.

Segundo Gehl (2017), o transporte é um item relevante na contabilidade verde, porque é responsável por um consumo massivo de energia, pelas consequentes emissões de carbono e pela pesada poluição. A priorização do pedestre e de bicicletas modificaria o perfil do setor de transportes, ajudaria de forma expressiva em políticas sustentáveis e apresentaria uma baixa taxa de ocupação da malha urbana.

Dentre as cidades que apresentam uma política de incentivo ao uso da bicicleta como meio de transporte, Bogotá na Colômbia é um exemplo de cidade onde o fluxo de pedestres e de ciclistas foi reforçado como resultado de uma ampla política de tráfego com objetivo de aumentar a mobilidade da grande maioria de seus habitantes, enquanto reduziam o impacto sobre o meio ambiente.

De acordo com Gehl (2017), é mais barato investir em infraestrutura para o ciclista do que para outros tipos de tráfegos. A priorização deste meio no cenário da cidade tornou-se evidente nos dias de hoje. O entendimento das partes interessadas de um projeto de implementação cicloviário é essencial para o bom desenvolvimento do mesmo.

Segundo o PMI (2013), identificar partes interessadas é o processo de reconhecer pessoas, grupos ou organizações que podem ter impacto ou serem impactados por uma decisão, atividade ou resultado do projeto, analisar e documentar as informações relevantes relativas aos seus interesses, nível de engajamento, interdependências, influência e seu impacto potencial no sucesso do projeto.

De acordo com o PMI (2013), o componente da parte interessada é um indivíduo, grupo ou organização que possa afetar ou sentir-se afetado por uma decisão, atividade, ou resultado de um projeto. Desta forma, existe a necessidade da organização e do gerente de projeto conhecer previamente quem são, o que esperam como resultado, que tipo de influência representam e quais os impactos estão relacionados a cada parte interessada.

De acordo com Montes (2017), as partes interessadas são os indivíduos e as or- 
ganizações ativamente envolvidos no projeto, ou seja, quem interessa ao seu projeto. Este irá atender necessidades das partes e elas são responsáveis por atender o objetivo desse. Podem ser positivamente ou negativamente afetados com a execução do projeto influenciando em seu resultado.

O grau de influência de cada parte interessada na perspectiva organizacional pode ser caracterizado pelas dimensões de legitimidade, poder e urgência, de acordo com Mitchell et al. (1997).

Dessa forma, Mitchell et al. (1997), desenvolve um estudo sobre a teoria de parte interessada onde várias classes das partes interessadas devem ser identificadas com base no domínio atribuído a um ou à combinação desses três atributos: poder, legitimidade e urgência, conforme ilustrado na figura 1 :

a) Poder: uma organização / indivíduo tem o poder, na medida em que tem ou pode ter acesso coercitivo, utilitário ou meios normativos para impor sua vontade no relacionamento.

b) Legitimidade: a noção de "legitimidade" refere-se vagamente a estruturas ou comportamentos geralmente aceitos e esperados socialmente, mas muitas vezes é acoplado implicitamente com o poder, quando as pessoas tentam avaliar a natureza dos relacionamentos na sociedade.

c) Urgência: existe apenas quando estiverem preenchidas duas condições: a primeira quando um relacionamento ou reclamação é de natureza urgente e segundo quando esse relacionamento ou reivindicação é importante ou crítica para a parte interessada. Combinada com a legitimidade promove o acesso aos canais de tomada de decisão e em combinação com o poder, incentiva a ação unilateral das partes interessadas. Em combinação com ambos, desencadeia reconhecimento recíproco e de ação entre as partes interessadas e gestores. 
Figura 1: Tipos de partes interessadas

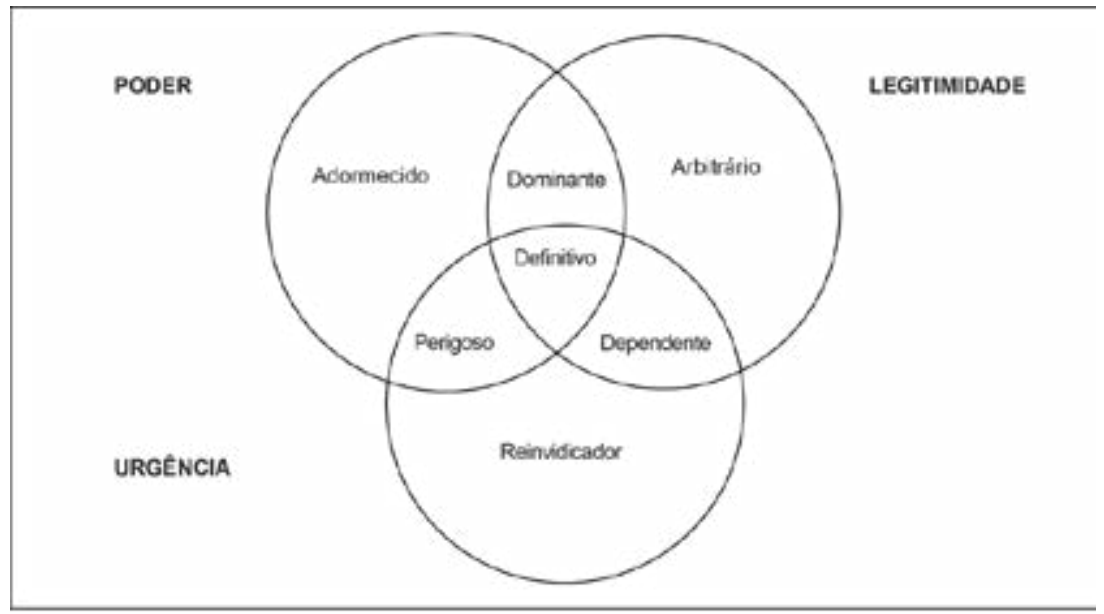

Fonte: (Mitchell et al., 1997)

Segundo Mitchell et al. (1997), a partir dessa definição, foram identificados sete tipos de partes interessadas ${ }_{\mathbf{L}}$ de modo a indicar que as entidades que não possuíssem nenhum dos três atributos não seriam consideradas partes interessadas e, por isso, não teriam relevância na administração da organização.

a) Parte interessada Adormecido: tem poder para impor sua vontade na organização, porém não tem legitimidade ou urgência e, assim, seu poder fica em desuso, tendo pouca ou nenhuma interação com a empresa. A empresa deve conhecer essa parte interessada para monitorar seu potencial em conseguir um segundo atributo.

b) Parte interessada Arbitrário: possui legitimidade, mas não tem poder de influenciar a empresa nem alega urgência. A atenção que deve ser dada a essa parte interessada diz respeito à responsabilidade social corporativa, pois tende a ser mais receptiva.

c) Parte interessada Reivindicador: quando o atributo mais importante na administração da parte interessada for urgência, ele é reivindicador. Sem poder e sem legitimidade, não deve atrapalhar tanto a empresa; porém deve ser monitorado quanto ao potencial de obter um segundo atributo. 
d) Parte interessada Dominante: tem sua influência na empresa assegurada pelo poder e pela legitimidade. Espera e recebe muita atenção da empresa.

e) Parte interessada Perigoso: quando há poder e urgência, porém, não existe a legitimidade, o que existe é uma parte interessada coercitiva e possivelmente violenta para a organização, o que pode ser um perigo, literalmente.

f) Parte interessada Dependente: tem alegações com urgência e legitimidade, porém depende do poder de uma outra parte interessada para ver suas reivindicações sendo levadas em consideração.

g) Parte interessada Definitivo: quando possui poder e legitimidade, já praticamente se configura como definitivo. Quando, além disso, alega urgência, deve-se dar atenção imediata e priorizada essa parte interessada.

Segundo Savage et al. (1991), a identificação dos tipos de partes interessadas em conjunto com a avaliação dos potenciais impactos positivos e negativos de cada parte em relação a organização, serviu como base para a classificação dos mesmos. As partes interessadas incluem indivíduos, grupos e outras organizações que têm interesse nas ações de uma empresa e que têm habilidade para influenciá-la. Para satisfazer as partes interessadas chaves, em primeiro momento é importante identificar aquelas que influenciam a organização. Em seguida deve-se realizar duas avaliações críticas, uma em relação ao potencial das partes interessadas em ameaçar a organização e o outra em relação ao potencial destes em cooperar com a empresa.

De acordo com o PMI (2013), a análise das partes interessadas segue as seguintes etapas:

a) Identificar todas as potenciais partes interessadas do projeto e as informações relevantes. As principais partes em geral são fáceis de identificar, a identificação de outras partes geralmente é feita através de entrevistas com as partes interessadas identificadas e expandindo a lista, até que todas as partes sejam incluídas.

b) Identificar o impacto ou apoio potencial que cada parte interessada poderia gerar e classifica-las a fim de definir uma estratégia de abordagem. 
c) Avaliar como as principais partes interessadas provavelmente reagirão ou responderão em várias situações, a fim de planejar como influenciá-las para aumentar seu apoio e mitigar os impactos negativos em potencial.

Assim como existem modelos classificatórios usados na análise das partes interessadas, como (PMI, 2014):

a) Grau de poder / interesse, que agrupa as partes interessadas com base no seu nível de autoridade e de preocupação em relação aos resultados do projeto.

b) Grau de poder / influência que agrupa as partes interessadas com base no seu nível de autoridade e no seu engajamento ativo no projeto.

c) Grau de influência / impacto que agrupa as partes interessadas com base no engajamento ativo no projeto e na habilidade de efetuar mudanças no planejamento ou na execução do projeto.

d) Modelo de relevância que descreve os tipos das partes interessadas com base no seu poder, na urgência e na legitimidade.

\subsection{Identificação de Variáveis Críticas}

Tendo como base o estudo de implementação do sistema cicloviário no entorno das estações do metrô, foram identificadas as principais variáveis críticas a partir do mapeamento de processo por BPMN e das matrizes SWOT e PESTEL.

\subsubsection{Mapeamento de Processo}

O mapeamento de processo é uma ferramenta gerencial e de comunicação que 
tem a finalidade de ajudar a melhorar os processos existentes. Este auxilia a empresa a enxergar os pontos fortes e fracos, além de melhorar o entendimento sobre os processos e aumentar a performance do projeto.

O mapeamento tem como base a proposta de implementação da malha cicloviária no entorno das estações do metrô. Foi dividido em cinco fases: planejamento, projeto, materiais, execução e uso e manutenção, conforme ilustrado na figura 2 . 
Figura 2: mapeamento de processos

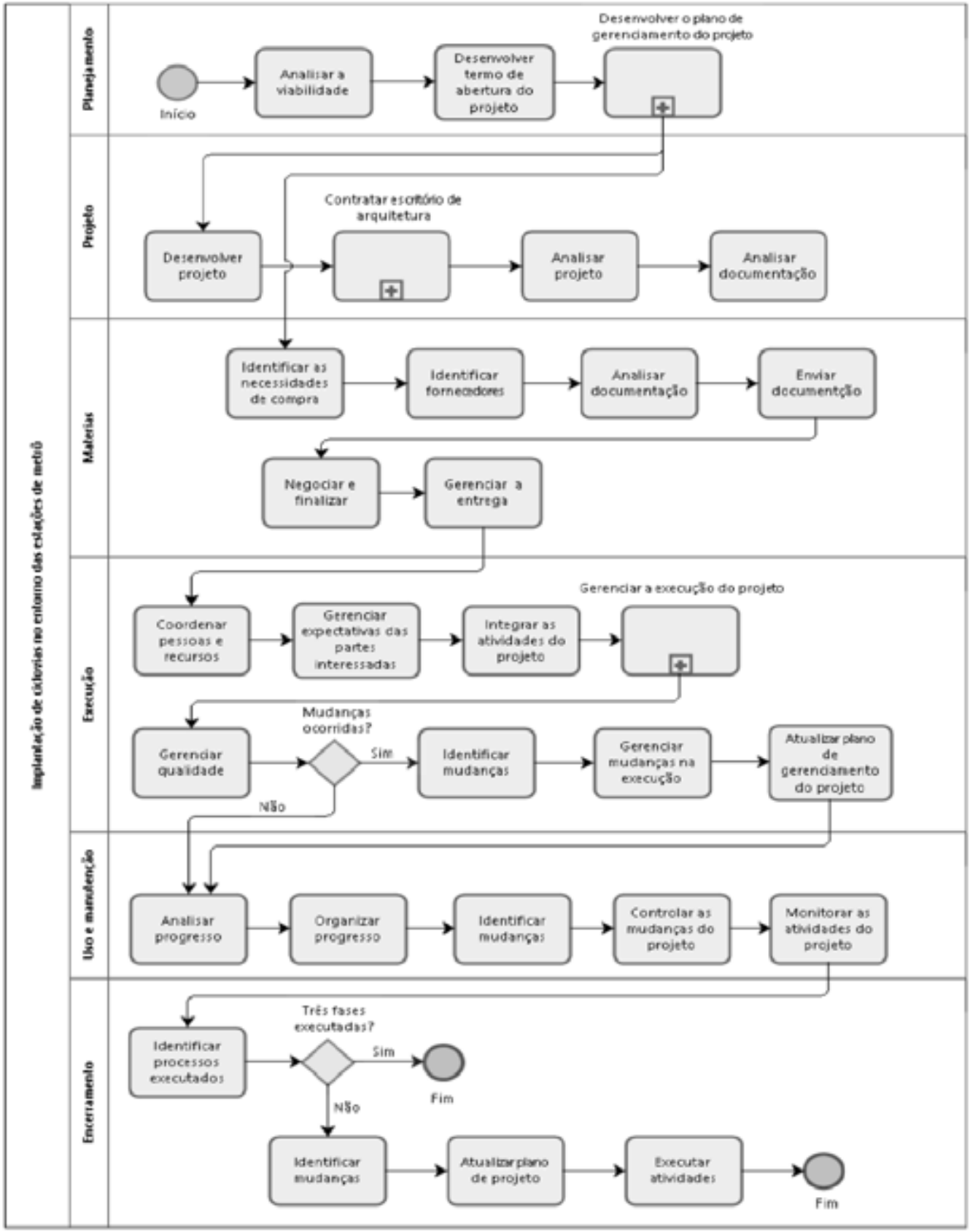

Fonte: (Os autor, 2018) 
O projeto inicia na fase de planejamento a partir de um estudo de viabilidade, seguido do desenvolvimento do termo de abertura e do plano de gerenciamento do projeto. Neste é documentado como será definido, validado e controlado além da realização dos seguintes processos: coleta de requisitos, definição do escopo, criação da EAP, validação do escopo e controle do mesmo.

Nesta etapa também são identificadas as partes interessadas, que consiste no processo de detectar pessoas, grupos ou organizações que podem impactar ou serem impactadas por uma decisão, atividade ou resultado do projeto, analisar e documentar informações relevantes relativas aos seus interesses, nível de engajamento, interdependências, influência e seu impacto potencial no êxito do projeto.

Outro processo deste subprocesso é o gerenciamento do cronograma, onde se estabelece as políticas, os procedimentos e a documentação para o planejamento, desenvolvimento, gerenciamento, execução e controle do projeto.

Em seguida vem os subprocessos de coleta de requisitos, que consiste em determinar, documentar e gerenciar as necessidades e requisitos das partes interessadas a fim de atender aos objetivos do projeto. Outro processo é o planejamento e gerenciamento de custos, onde inclui os processos do planejamento, os orçamentos, estimativas, financiamentos, gerenciamento e controle dos custos, de modo a visar que o projeto seja finalizado dentro do orçamento estipulado para o mesmo.

Neste subprocesso também é realizado o gerenciamento de riscos do projeto, em que incluem os processos de planejamento, identificação, análise, planejamento de respostas e controle de riscos de um projeto. Todos esses processos estão inseridos no subprocesso de plano de gerenciamento do projeto. Com este finalizado inicia a fase do projeto simultâneo com a de materiais, conforme ilustrado na figura 2 .

A fase de projeto inicia a partir do desenvolvimento do projeto, seguido da contratação do escritório de arquitetura, análise do projeto e análise da documentação.

A fase de materiais inicia a partir da identificação das necessidades de compra, seguido do processo de identificar fornecedores, análise de documentação, envio de documentos, negociação, finalização e gerenciamento da entrega. Em sequência inicia a etapa de execução. 
A fase de execução configura a partir da coordenação de pessoas e recursos, seguida do gerenciamento das partes interessadas, neste processo é importante identificar os interesses dos mesmos, verificar se houve mudanças nas estratégias, se surgiram novas partes interessadas, se existiram conflitos e se estes foram solucionados de maneira eficiente.

Em sequência o processo de integração das atividades do projeto seguido do subprocesso de gerenciamento e execução do projeto e do gerenciamento de qualidade. O projeto se encerra caso não haja mudança, ao contrário é necessário identificá-las, gerenciá-las e atualizar o plano de projeto, para que o mesmo seja conduzido de forma correta até o seu encerramento.

A etapa de uso e manutenção é composta pelos processos: análise e organização do progresso, identificação das mudanças, controle das mudanças do projeto e monitoramento das atividades do projeto.

O encerramento corresponde a sexta e última etapa nele é realizado a identificação dos processos executados, sendo assim o projeto se da por encerrado ao fim da execução das três fases.

\subsubsection{Matriz SWOT}

A análise SWOT é muito utilizada no planejamento estratégico das empresas ou de novos projetos, pois consiste na realização de um diagnóstico completo sobre o negócio e o ambiente que o cerca. Com isso, o empreendedor tem um embasamento para formular suas estratégias de gestão e marketing com mais segurança.

O resultado da análise é a criação da matriz, também chamada de Matriz SWOT, que ajuda a identificar os principais fatores internos a serem trabalhados e os pontos externos que demandam atenção.

Segundo Baptista (2008), o conjunto de interações entre os fatores internos (forças e fraquezas) e externos (oportunidades e ameaças) à organização, é efetuado com o 
auxílio da matriz de análise estratégica através de ponderações das interações das forças e fraquezas com as oportunidades e ameaças denominada de Matriz SWOT.

Conforme ilustrado na figura 3 foi elaborada uma matriz SWOT (Fernandes, 2012) do tema abordado neste trabalho, tendo quatro forças constituem o ambiente interno do projeto. No campo direito apresentam-se as quatro oportunidades escolhidas, em seguida as quatro ameaças, constituindo-se o ambiente externo ao projeto. A partir destes fatores é possível compreender a matriz SWOT 8x8, de 64 cruzamentos.

O primeiro quadrante indica a existência de potencialidade de ação ofensiva, ou capacidade ofensiva, apontando o quanto as forças podem ajudar a aproveitar as oportunidades do mercado.

O segundo indica o potencial da capacidade defensiva demonstrando o quanto o conjunto de forças está preparado para rechaçar as ameaças que se aproximam.

O terceiro quadrante identifica o nível de debilidade da capacidade ofensiva indicando o quanto as fraquezas podem causar problemas para o aproveitamento das oportunidades.

O quarto apresenta o nível de vulnerabilidade da organização indicando o quanto as fraquezas podem amplificar o efeito das ameaças.

Esta matriz e seus princípios foram utilizados como referência na elaboração do plano estratégico deste trabalho, voltado para a proposta de implementação do sistema cicloviário no entorno das estações do metrô da cidade do Rio de Janeiro. 
Figura 3: Matriz SWOT

\begin{tabular}{|c|c|c|c|c|c|c|c|c|c|c|}
\hline & AMEIENTE EXTERNO & \multicolumn{4}{|c|}{ OPORTUNIDADES } & \multicolumn{4}{|c|}{ AMEACAS } & \\
\hline 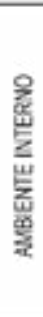 & $\begin{array}{l}\text { OPORTUNIDADESE } \\
\text { AMEACAS } \\
\text { FORCAAS } \\
\text { FRAQUEZAS }\end{array}$ & 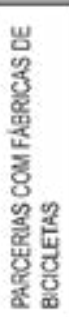 & 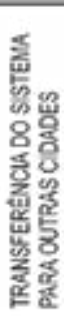 & 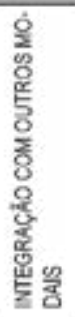 & 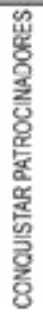 & 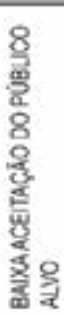 & 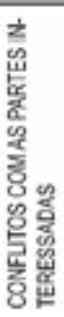 & 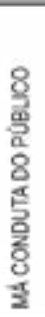 & 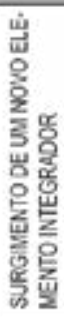 & $\frac{\frac{m}{2}}{\frac{c}{6}}$ \\
\hline \multirow{4}{*}{$\begin{array}{l}\frac{2}{2} \\
\text { 훙 }\end{array}$} & INTEGRAÇĀO COM MODAL & 2 & 2 & 2 & 2 & 2 & 1 & 0 & $\circ$ & 11 \\
\hline & ACESSIBILIDADE A SERVIÇOS & 1 & 1 & 2 & 2 & 2 & 1 & 1 & o & 10 \\
\hline & $\begin{array}{l}\text { REDUCĂO DA FROTA DE AUTOMO- } \\
\text { VEIS }\end{array}$ & 2 & 2 & 2 & 2 & 2 & 1 & 0 & 0 & 11 \\
\hline & $\begin{array}{l}\text { MEL HORIA NA QUALIDADE DE VIDA } \\
\text { DO USUARIO }\end{array}$ & 2 & 1 & 1 & 1 & 1 & 1 & 0 & 1 & B \\
\hline \multirow{4}{*}{$\frac{\sqrt[n]{4}}{\frac{3}{3}}$} & INSEGURANÇA & 1 & 1 & 1 & 1 & 2 & 1 & 0 & 2 & 9 \\
\hline & ALTO RISCO DE MUDANC,AS & 0 & 0 & 1 & 1 & 2 & 2 & 1 & 0 & 7 \\
\hline & $\begin{array}{l}\text { IMPRECISĀO NO PRAZO DE CON- } \\
\text { CLUSÄO }\end{array}$ & 1 & 1 & 1 & 1 & 1 & 2 & 0 & o & 7 \\
\hline & NÃO É AUTOSSUFICIENTE & 0 & 0 & 0 & 0 & 0 & o & 2 & 0 & 0 \\
\hline \multicolumn{2}{|r|}{ TOTAIS } & 5 & 4 & 4 & 4 & 2 & -1 & -2 & -1 & \\
\hline
\end{tabular}

Fonte: (Os autor, 2018)

Com base nos resultados da matriz SWOT é possível identificar duas oportunidades que envolvem as partes interessadas como: parcerias com fábricas de bicicleta e conquista de patrocinadores, ambos importantes para o crescimento e desenvolvimento do sistema.

As forças que apontam maior pontuação devem ser vistas como os principais pontos de apoio para impulsionar o projeto. A análise horizontal demonstra que as forças "integração com modal" e "redução da frota de automóveis" são as mais evidentes como elementos essenciais desse projeto.

Após a integração com o modal (figura 3 ) segue "acessibilidade a serviços" e "melhoria na qualidade de vida do usuário", forma um conjunto das quatros forças que apresentam um valor igual ao superior a metade do valor máximo possível.

Uma determinada força pode se apresentar com valor considerável frente ao am- 
biente externo, é preciso exercitar a análise em cada grupo de oportunidades e de ameaças, de modo que a força pode se apresentar muito boa para a captura de oportunidades e demonstrar insuficiente para o bloqueio das ameaças ou de parte delas.

Tendo como base a matriz ilustrada na figura 3 é necessário que a organização observe as quatro forças, pois as mesmas demonstram fragilidade antes as ameaças listadas.

A análise de cada fraqueza é realizada com base nos valores apontados em cada cruzamento da matriz, adicionando os valores do cruzamento com as oportunidades, os valores anotados para o cruzamento com as ameaças. Quanto maior for o valor apresentado maior é a percepção do impacto da fraqueza para os elencados.

A fraqueza "insegurança" é a mais expressiva da matriz SWOT, seguida pelas fraquezas "alto risco de mudanças" e "imprecisão no prazo de conclusão". O conjunto de fraquezas de uma forma geral não atrapalha a captura das oportunidades e não intensifica o risco das ameaças listadas.

Vale ressaltar que a fraqueza "insegurança" e "imprecisão no prazo de conclusão" apresenta para todos os cruzamentos com as oportunidades a mesma pontuação, o que demonstra que a mesma não atrapalha a captura de oportunidades.

A análise de cada um dos fatores permite a identificação dos pontos positivos, como também o conhecimento dos aspectos negativos. Essa análise é um dos principais benefícios da matriz SWOT.

\subsubsection{Matriz PESTEL}

Ao contrário da Matriz SWOT, a PESTEL direciona-se diretamente aos fatores macros do ambiente externo que podem afetar o projeto. Ou seja, proporciona uma visão mais abrangente dos fatores externos que podem afetar o projeto, impedir seu desenvolvimento ou levá-lo ao declínio, além de identificar novos rumos. 
Baseado nisso que na relação SWOT x PESTEL uma ferramenta não elimina a outra. Ambas as matrizes são métodos de planejamento que proporcionam uma visão de fatores que podem interferir na execução de um plano ou projeto.

A partir da análise PESTEL, pode se reconhecer diversos fatores relacionados a este ponto crítico, como: as políticas de negociação, crescimento da indústria, taxa de crescimento, tabus culturais, atitudes e opiniões dos usuários, tendência de estilos de vida, pesquisa e inovação de informação e comunicação, conforme ilustrado na figura 4.

Os principais objetivos nas pesquisas de partes interessadas têm sido identificar quem são as partes interessadas da empresa e determinar quais tipos de influência elas exercem. (ROWLEY,1997). A figura 5 e 6 apresentam as partes interessadas do projeto a partir dos resultados das análises SWOT e PESTEL, com base no modelo proposto por Mitchel et al. (1997).

Figura 4: matriz PESTEL

\begin{tabular}{|c|c|c|c|c|c|}
\hline $\begin{array}{l}\text { Politicas governa- } \\
\text { mentais }\end{array}$ & Economia local & $\begin{array}{l}\text { Taxa de crescimen- } \\
\text { to }\end{array}$ & $\begin{array}{l}\text { Pesquisas e inova- } \\
\text { çăo }\end{array}$ & Sustentablidado & $\begin{array}{l}\text { Legislaçăo em vi- } \\
\text { gor }\end{array}$ \\
\hline $\begin{array}{l}\text { Mudanças de go- } \\
\text { verno / eleiçós }\end{array}$ & Inflaçăo & Tabus culturais & $\begin{array}{l}\text { Tecnologia emer- } \\
\text { gente }\end{array}$ & $\begin{array}{l}\text { Regulamentos } \\
\text { ambientass }\end{array}$ & Legislaçắo futura \\
\hline $\begin{array}{l}\text { Politicas e negocia- } \\
\text { çdo }\end{array}$ & $\begin{array}{l}\text { Crescimento da } \\
\text { industria }\end{array}$ & $\begin{array}{l}\text { Atitudes e opinióes } \\
\text { dos usuânos }\end{array}$ & $\begin{array}{l}\text { Maturidade da tec- } \\
\text { nologia }\end{array}$ & $\begin{array}{l}\text { Qualidade de vida } \\
\text { do usuário }\end{array}$ & Leis trabalhistas \\
\hline Financiamento & $\begin{array}{l}\text { Taxas de importa- } \\
\text { pə̄o e exportaçāo }\end{array}$ & $\begin{array}{l}\text { Tendencia de esti- } \\
\text { los de vida }\end{array}$ & $\begin{array}{l}\text { Informaçăio e comu- } \\
\text { nicaģbెo }\end{array}$ & $\begin{array}{l}\text { Reduçäo da emis- } \\
\text { sảo de cartono }\end{array}$ & $\begin{array}{l}\text { Proteçalo aos consu- } \\
\text { micicres }\end{array}$ \\
\hline
\end{tabular}

Fonte: (Os autor, 2018) 
Figura 5: classificação das partes interessadas

\begin{tabular}{|c|c|c|c|c|}
\hline STAKEHOLDER & POOER & LEGTIMEDADE & UROENCLA & CLAASSIFICAÇAOO \\
\hline FABRICAS DE UICICLETAS & & $x$ & & ARBITRARIO \\
\hline PATROCINNDORES & & $x$ & & NRGITRARIO \\
\hline MCRADOPES DAREGLAO & & $x$ & $\mathrm{x}$ & DEPENDENIE \\
\hline GOVERNO & $x$ & $x$ & $x$ & DEFINITIVO \\
\hline USUAFIOS & & $x$ & $x$ & DCPENDENTE \\
\hline INVESTIDORES & $x$ & $x$ & & DOMINEANTE \\
\hline CONCORRENTES & & $x$ & & ARBITRARIO \\
\hline FUNCIONÁRIOS & & $\mathrm{x}$ & $x$ & DEPENDENTE \\
\hline FORNECEDORES & & $x$ & $\mathrm{x}$ & DCPENDENTE \\
\hline Mioin & & $x$ & & ARESIRALETO \\
\hline PROPRIETÁREOS DA AEGLIOO & & & $x$ & REIVINDICADOR \\
\hline SINDICATO & $x$ & & & NDCRMECIDO \\
\hline ONGS & & $x$ & $x$ & DEPENOENTE \\
\hline ORGÁOS AMEIENTAIS & $x$ & $x$ & $x$ & DEFINITIVO \\
\hline
\end{tabular}

Fonte: (Os autor, 2018)

A figura 6 representa uma análise das partes interessadas em relação aos fatores que afetam seu potencial em ameaçar e cooperar com o projeto, segundo o modelo de Savage et al. (1991).

As partes interessadas foram classificadas (figura 7) de acordo com os princípios de Savage (1991), apresentados anteriormente neste trabalho. As fábricas de bicicletas, patrocinadores, governo e usuários, apresentam um alto potencial de ameaça quanto de colaboração, o que demonstra a importância que estes possuem em relação ao projeto. Contrapondo, moradores da região, mídia, proprietários da região, sindicato e ONGs possuem baixo potencial tanto em ameaçar quanto em colaborar. 
Figura 6: Análise das partes interessadas

\begin{tabular}{|c|c|c|c|}
\hline STAKEHOLDER & $\begin{array}{l}\text { POTENCIAL EM } \\
\text { AMEAÇAR }\end{array}$ & $\begin{array}{l}\text { POTENCIAL EM } \\
\text { COLABORAR }\end{array}$ & CLASSIFICAÇĀOO \\
\hline FABBRICAS DE BICICLETAS & ALTO & ALTO & AMBiguO \\
\hline PATROCINADORES & ALTO & ALTO & AMAIGUO \\
\hline MORADORES DA REGIÃO & BAIXO & BAIXO & MARGINAL \\
\hline GOVERNO & ALTO & ALTO & AMBicuo \\
\hline USUARRIOS & ALTO & ALTO & Ambiguo \\
\hline INVESTIDCRES & ALTO & ALTO & ambiguo \\
\hline CONCORRENIES & ALTO & BAIXO & INDISPOSTO \\
\hline FUNCIONARIOS & BADXO & ALTO & DISPOSTO \\
\hline FORNECEDORES & BAIXO & ALTO & DISPOSTO \\
\hline MIDIA & BALXO & BAIXO & MARGINAL. \\
\hline PROPRIETÁRIOS DA REGIAOO & BADXO & BAIXO & MNRGINAL \\
\hline SINDICATO & BADXO & BAIXO & MARGINAL \\
\hline ONGS & BAIXO & BAIXO & MARGINAL \\
\hline ORGĀOS AMBIENTAIS & ALTO & BAIXO & INDISPOSTO \\
\hline
\end{tabular}

Fonte: (Os autor, 2018)

A partir desta análise é possível colocar as partes interessadas de acordo com o seu potencial em cooperar e/ou ameaçar o projeto de implementação de ciclovias no entorno das estações do metrô. 
Figura 7: classes das partes interessadas

\begin{tabular}{|c|c|c|c|}
\hline \multirow{3}{*}{ 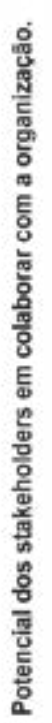 } & & \multicolumn{2}{|c|}{ Potencial dos stakeholders em AMEAÇAR a organização. } \\
\hline & ALTO & $\begin{array}{l}\text { TIPO 4: AMBIGUO } \\
\text { Estratégia: } \\
\text { Colaborar } \\
\text { Fabncas de bicicletas } \\
\text { Patrocinadores } \\
\text { Govemo } \\
\text { Usuários } \\
\text { Investicores }\end{array}$ & $\begin{array}{l}\text { TIPO 1: DISPOSTOS A APOIAR } \\
\text { Estratégia: } \\
\text { Envolver } \\
\text { Funcionários } \\
\text { Fornecedores }\end{array}$ \\
\hline & BAIXO & $\begin{array}{l}\text { TIPO 3: INDISPOSTOS A } \\
\text { APOIAR } \\
\text { Estrategia: } \\
\text { Defender } \\
\text { Concorrentes } \\
\text { Orgalos ambientais }\end{array}$ & $\begin{array}{l}\text { TIPO 2: MARGINAIS } \\
\text { Estratćgia: } \\
\text { Monitorar } \\
\text { Moradores da região } \\
\text { Midia } \\
\text { Prcprietários da regiảo } \\
\text { Sindicato } \\
\text { ONGs }\end{array}$ \\
\hline
\end{tabular}

Fonte: (Os autor, 2018)

Com base na figura 7 é possível concluir que o grupo das partes interessadas dispostos a apoiar estão os funcionários e fornecedores. Como o potencial em cooperar desse grupo é alto e o de ameaçar é baixo, fica evidente que a construção de parcerias com eles é facilitada por essas questões e deve ser praticada sempre que necessário.

Já o grupo dos marginais configuram os moradores da região, mídia, proprietários da região, sindicato e ONGs. É necessário monitorar esse grupo, antes de tentar envolvê-los nos propósitos do projeto, pois eles possuem baixo potencial em cooperar. No grupo dos indispostos a apoiar os concorrentes e os órgãos ambientais e no dos ambíguos, fábricas de bicicletas, patrocinadores, governo, usuários e investidores.

A ausência de uma gestão transparente pode gerar conflitos de relacionamento entre o projeto e suas partes interessadas. Ao alinhar à sua estratégia ações de transparência, as partes interessadas nivelarão seus conceitos sobre o projeto e, em decorrência disto, o diálogo será facilitado, de modo que a gestão de partes interessadas terá vantagens neste processo que consiste em maior aproximação entre as percepções das partes interessadas internas e externas. 
2.3 Situação Atual (Discussão / Resultados)

O trabalho tem como objetivo identificar as partes interessadas em um estudo de caso de um projeto de implementação do sistema cicloviário no entorno das estações do metrô da cidade do Rio de Janeiro, de modo a gerar uma integração entre os meios.

Segundo o arquiteto Gehl (2017), uma simples mudança na política urbana reforçará a qualidade urbana e os objetivos sociais mais importantes. Além de outros benefícios um convite mais direto para caminhar e pedalar nas cidades pode ser feito de forma rápida e econômica.

O incentivo ao uso da bicicleta provoca um aumento no número de ciclistas, principalmente em pequenos trechos, reduzindo o número de automóveis nas proximidades das estações, consequentemente diminuindo a emissão de gases poluentes e melhora na qualidade de vida das pessoas. Tendo como foco a identificação das partes interessadas, em primeiro momento foi realizada uma análise SWOT seguida da PESTEL de modo a garantir um melhor entendimento da proposta estudada.

A partir da identificação as partes interessadas foram distribuídos nos sete grupos estudados: adormecido, dominante, arbitrário, definitivo, dependente, perigoso e reivindicador. De acordo com o seu grau de poder, legitimidade e urgência.

Em seguida foi realizado uma avaliação crítica em relação ao potencial das partes interessadas em ameaçar a organização e ao potencial destes em cooperar com a empresa. Sendo classificados em quatro grupos: dispostos a apoiar, marginais, indispostos a apoiar e ambíguo de acordo com o alto e baixo poder de ameaça e cooperação. No terceiro momento as partes interessadas foram listadas de acordo com os resultados das análises SWOT e PESTEL e classificadas conforme o grau de poder, legitimidade e urgência.

\section{CONSIDERAÇÕES FINAIS}


A cidade do Rio de Janeiro convive diariamente com grandes congestionamentos, principalmente nos horários de pico, problema este encontrado em diversas metrópoles brasileiras. A bicicleta hoje é vista como elemento integrador entre os modais, de modo a configurar um sistema unificado em rede. $O$ projeto visa incentivar o uso da mesma no tecido urbano da cidade, mas como também nos laboratórios de pesquisas. É fundamental estimular esses estudos na sociedade de hoje, de modo a contribuir na busca de cidades vivas.

A identificação das partes interessadas é fundamental para uma melhor compreensão do projeto e desenvolvimento do mesmo. Entende-las e analisa-las garante um menor risco de ameaça e uma melhor cooperação das partes.

\section{REFERÊNCIAS}

BALDAM, R. Gerenciamento de processos de negócio BPM. 1. Ed. Elsevier: 2014.

CHIAVENATO, I. Administração nos novos tempos. 3. Ed. São Paulo: Makron, 2014.

CHIAVENATO, I. Introdução a teoria geral da administração. 4. Ed. São Paulo: Makron, 1993.

GEHL, J. Cidade para pessoas. 3. Ed. Perspectiva. 2017. 
KLUYVER, C. Estratégia uma visão executiva. $2^{\circ}$ Edição. Pearson, 2007.

MITCHELL, R. K; AGLE, B. R; WOOD, D. J. Toward a theory of stakeholder identification and salience: defining the principle of who and what really counts. Academy of Management Review, v.22, 1997.

OLIVEIRA, D. Planejamento estratégico conceitos metodologia práticas. 12. Ed. Atlas, 1998.

PMI, Project Management Institute. Um guia do conhecimento em gerenciamento de projetos. 5. Ed.Saraiva. 2013.

SAVAGE, G. NIX, T. WHITEHEAD, C. and BLAIR. J., "Strategies for assessing and managing organizational stakeholders", Academy of Management Executive, Vol.5, 1991.

SORDI, J. Gestão por processos uma abordagem da moderna administração. 2. Ed. Saraiva, 2008.

THOMPSON,
A.

Planejamento estratégi- 
co, elaboração, implementação e execução. Pioneira, 2002.

UNOPAR Cient., Ciênc. Juríd. Empres., Londrina, v. 13, n. 2, p. 57-68, Set. 2012 